\title{
A double isotope technique for the evaluation of drug action on gastric evacuation and small bowel propulsion studied in the rat
}

\author{
FOLKE NILSSON AND HENRY JOHANSSON \\ From the Department of Surgery, University Hospital of Uppsala, Uppsala, Sweden
}

SUMMARY A method to measure simultaneously gastric evacuation and small bowel propulsion in the rat is presented. The value of the method in testing drug action is described. The effect of an antidiarrhoeal agent, diphenoxylate, was analysed and it was shown that it retarded small bowel propulsion without influencing gastric evacuation.

Quantitative analyses of gastrointestinal propulsive motility can be made by graphic recording of the distribution of an intragastrically administered nonabsorbable radioactive solution. Such a method (Derblom, Johansson, and Nylander, 1966) was developed in our laboratory and employed for studies of gastric emptying and propulsive intestinal motility in the rat under various experimental conditions of surgical interest (Johansson, 1966; Nylander, 1967; Nylander and Wikström, 1967; Lindquist, 1968). Although this method gives a valuable total picture of gastrointestinal passage, it is inadequate for evaluating a possible specific effect on small bowel propulsion as the rate of gastric emptying influences small bowel propulsion.

In order to study small bowel propulsion more specifically, the test solution was administered directly into the duodenum (Nilsson, Johansson, Johnson, Lindquist, Nylander, and Wikström, 1970; Nilsson, 1972). Further modification of this method and of the recording equipment has permitted simultaneous studies of gastric evacuation and small bowel propulsion in one and the same animal (Nilsson, Jung, and Lundquist, 1973).

An antidiarrhoeal agent, diphenoxylate, in wide clinical use, was chosen to illustrate the improved method for studying the effect of a drug on gastric emptying and small bowel propulsion simultaneously.

Diphenoxylate, 2,2-diphenyl-1-4-(4-carbethoxy-4phenyl)-piperidino butyronitrile hydrochloride, was synthesized in 1959 by Janssen, Jageneau, and Huygens, who first demonstrated its antidiarrhoeal activity.

Received for publication 21 February 1973.

\section{Materials and Methods}

Male albino rats (Sprague-Dawley) weighing about $225 \mathrm{~g}$ were used throughout. They were divided into three groups. The first group, of 17 animals, was treated with a single dose of $14 \mathrm{mg}$ diphenoxylate (Retardin)/kg body weight. The drug was dissolved in Tween 80 and $3.0 \mathrm{ml}$ of solution administered. The remaining two groups of seven animals each served as controls and were treated with either $3.0 \mathrm{ml}$ Tween 80 or $3.0 \mathrm{ml}$ saline.

The test substance used in the recording of gastrointestinal motility was a mixture of radioactive material, polyvinylpyrrolidone (PVP) labelled with ${ }^{125} \mathrm{I}$ or ${ }^{131} \mathrm{I}$, and a test meal of standard composition, viscosity, and pH (Derblom et al, 1966; Nilsson et al, 1973).

The operative procedure and the equipment used to record gastric emptying and small intestinal propulsion have been described in detail elsewhere (Nilsson, 1972; Nilsson et al, 1973). On day 1, an upper abdominal incision was made and via a duodenotomy a tube was placed $40 \mathrm{~mm}$ distal to the pylorus. The tube was tunnelled subcutaneously to emerge at the animal's neck, where it was protected by a cap. On day 3 , diphenoxylate, Tween 80 , or saline was given via an oro-gastric tube and thereafter the animal was denied access to food but was permitted to drink freely for 16 hours. The rats were then completely starved for two hours until ${ }^{131}$ I-PVP $(1.0 \mathrm{ml})$ was given via an oro-gastric tube to the stomach of the conscious animal and at the same time ${ }^{125}$ I-PVP $(0.25 \mathrm{ml})$ was given via the duodenal tube. The animals were killed 15 minutes later by de- 
capitation under ether anaesthesia. The stomach and small bowel were then excised in continuity and stretched out on a Perspex plate. Radioactivity remaining in the stomach and the distribution of the activity in the small intestine were recorded with a scanning scintillation counter. The detector pulses were fed to two single-channel analysers connected to two scalers and recorded digitally on punched paper tape. The paper tapes were processed in a Siemens $\mathbf{3 0 5}$ computer. The relative lengths of small bowel passed by 75,50 , and $25 \%$ of the dose of labelled PVP deposited in the duodenum were taken as an index of small bowel propulsion. Student's $t$ test was used to examine the differences in unpaired values in the length of small bowel traversed in the three different groups.

\section{Results}

The results are presented in the table.

\begin{tabular}{llllll}
\hline $\begin{array}{l}\text { Groups } \\
\text { Treated with }\end{array}$ & $E^{s}$ & $D^{d}{ }_{75}$ & $D^{d}{ }_{s 0}$ & $D^{d}$ \\
\hline $\begin{array}{l}\text { Diphenoxylate } \\
14 \mathrm{mg} / \mathrm{kg} \\
(\mathrm{n}=17)\end{array}$ & $74.2 \pm 10.9^{1}$ & $41.2 \pm 10.4$ & $52.3 \pm 11.5$ & $59.7 \pm 13.1$ \\
$\begin{array}{c}\text { Tween } 80 \\
(\mathrm{n}=7)\end{array}$ & $74.7 \pm 9.8$ & $52.5 \pm 7.3$ & $63.8 \pm 5.8$ & $75.0 \pm 8.0$ \\
$\begin{array}{c}\text { Saline } \\
(\mathrm{n}=7)\end{array}$ & $78.2 \pm 8.4$ & $59.7 \pm 6.4$ & $68.7 \pm 7.0$ & $76.8 \pm 8.6$ \\
\hline
\end{tabular}

Table Percentage gastric evacuation $\left(E^{*}\right)$ and small bowel length passed by 75,50 , and $25 \%$ of activity deposited in duodenum $\left(D^{d}{ }_{75}, D^{d}{ }_{50}, D^{d}{ }_{25}\right)$

${ }^{1}$ Mean values with SDs.

\section{GASTRIC EMPTYING}

No significant differences between the diphenoxylate-treated animals and the two control groups were noted. The rate of gastric emptying was not significantly different in the two control groups (P > 0.05).

SMALL BOWEL PROPULSION

Significant differences were observed between diphenoxylate-treated and control animals. In the group of diphenoxylate-treated $(14 \mathrm{mg} / \mathrm{kg})$ animals, shorter lengths of small bowel were passed by 75, 50 , and $25 \%$ of the duodenal dose of radioactivity. The orders of significance were $P<0.025, P<0.025$, and $P<0.01$, respectively, when diphenoxylatetreated animals were compared with animals treated with Tween 80. Compared with saline-treated animals the corresponding levels of significance were $\mathrm{P}<0.005, \mathrm{P}<0.005$, and $\mathrm{P}<0.005$, respectively.
No significant differences could be seen between the control groups $(P>0.05)$.

\section{Discussion}

The functional significance of different types of well defined pressure waves involved in the motility of the small intestine is not clearly established. Thus, the effect of a drug on the pressure patterns can only give an approximate index of the likely clinical effect (Connell, 1961). Intraluminal pressures can be registered with balloons, open-tip catheters, and by endoradiosondes, which are propelled through the gastrointestinal tract. Bárány and Jacobson (1964) measured the propagation of an endoradiosonde in man but were unable to correlate pressure activity with supposed distance travelled.

The net effect of a drug on the gastrointestinal canal can either be studied by measurements of transit time or by registration of the distribution of an indicator substance within the tract at varying intervals after its administration. Janssen et al (1959) showed in mice that the administration of diphenoxylate increased the transit time of a charcoal suspension from the stomach to the appendix. They also demonstrated a decrease in the number of faecal pellets passed by rats after a dose of the drug. This altered propulsion may be due to the drug's action on any part of the gastrointestinal tract, and it is impossible to distinguish whether the drug acted primarily on gastric emptying, small bowel propulsion, or colonic motility. In our experiments we are able, by using a double nuclide technique, to study different levels of the gastrointestinal tract simultaneously and so determine the site of action of a given drug. We have not yet investigated colonic activity.

We chose diphenoxylate to evaluate this new method of testing drug action on gastrointestinal propulsive motility because we have used it, clinically, as an antidiarrhoeal agent for several years, and wished to know where its action was exerted. Moreover, the drug was obtainable in a suitable form for intragastric administration.

Our results showed that the delay in gastrointestinal transit time, as determined by Janssen et al (1959) after diphenoxylate therapy $(14 \mathrm{mg} / \mathrm{kg})$ in the rat, was due to delayed small bowel propulsion. Gastric evacuation was unaffected by the same dose of the drug. Heykants, Lewi, and Janssen (1972) have pointed out that in fact the main therapeutic effect is probably exerted by the active metabolite, diphenoxine. This is consistent with our observations of diminished small bowel propulsion 18 hours after the administration of the drug.

The present study demonstrates the existence of a 
specific action of the drug on one part of gastrointestinal function. The double isotope technique is useful to discriminate between the effects of a drug on gastric evacuation and small bowel propulsion.

\section{Diphenoxylate (Retardin) was kindly supplied by} AB Leo, Helsingborg, Sweden.

\section{References}

Bárány, F., and Jacobson, B. (1964). Endoradiosonde study of propulsion and pressure activity induced by test meals, Prostigmine, and diphenoxylate in the small intestine. Gut, 5, 90-95.

Connell, A. M. (1961). The motility of the small intestine. Postgrad. med. J., 37, 703-716.

Derblom, H., Johansson, H., and Nylander, G. (1966). A simple method of recording quantitatively certain gastrointestinal motility functions in the rat. Acta chir. scand., 132, 154-165.

Heykants, J. J. P., Lewi, P. J., and Janssen, P. A. J. (1972). Difenoxine $\left(R^{15103}\right)$, the active metabolite of Diphenoxylate $\left(R^{1132}\right)$. Arzneimittel-Forsch. 22, 520-526.

Janssen, P. A. J., Jageneau, A. H., and Huygens, J. (1959). Synthetic anti-diarrhoeal agents. I. Some pharmacological properties of R 1132 and related compounds. J. med. pharm. Chem., 1, 299308.

Johansson, H. (1966). Gastrointestinal motility function related to thyroid activity. An experimental study in the rat. Acta chir. scand., Suppl. 359.

Lindquist, B. (1968). Propulsive gastrointestinal motility related to retroperitoneal irritation: an experimental study in the rat. Acta chir. scand., Suppl. 384.

Nilsson, F. (1972). Small bowel propulsive motility in the rat. Studies with open and closed pylorus. Acta chir. scand., 138, 830-833.

Nilsson, F., Johansson, H., Johnson, L., Lindquist, B., Nylander, G., and Wikström, S. (1970). Ventrikeltömningens betydelse för gastrointestinal propulsion hos råtta. Nord. Med., 83, 580.

Nilsson, F., Jung, B., and Lundquist, H. (1973). Measurements of gastric evacuation and small bowel propulsion with a double nuclide technique. A methodological study in the rat. Acta chir. scand., in press.

Nylander, G. (1967). Gastric evacuation and propulsive intestinal motility following resection of the small intestine in the rat. Acta chir. scand., 133, 131-138.

Nylander, G., and Wikström, S. (1967). Gastric emptying and propulsive intestinal motility following partial gastric resection, gastro-enteroanastomosis and abdominal 'trunk' vagotomy in the rat. Acta chir. scand., 133, 41-54. 